\title{
Transformational Leadership and Innovation: An Empirical Study of Direct and Indirect Effects in HR Consulting Companies
}

\author{
Esin Akay $^{1} \&$ Ayse Gonul Demirel ${ }^{1}$ \\ ${ }^{1}$ Faculty of Economics \& Admin, Sciences, Business Administration Department, Yeditepe University, Istanbul, \\ Turkey \\ Correspondence: Ayse Gonul Demirel, Faculty of Economics \& Admin. Sciences, Business Administration \\ Department, Yeditepe University, 26 August Campus, 34755 Atasehir, Istanbul, Turkey. E-mail: \\ gonuld@yeditepe.edu.tr
}

Received: October 12, 2017

Accepted: December 18, 2017 Online Published: December 20, 2017

doi:10.5539/ijbm.v13n1p131

URL: https://doi.org/10.5539/ijbm.v13n1p131

\begin{abstract}
This study aims to examine the influence of transformational leadership on organizational innovation through the mediating effect of organizational learning and knowledge management in Turkish HR consulting companies. Sample is selected from small, medium size and large HR consulting companies located in Istanbul. Structural equation modeling and bootstrapping is used for data analysis. The research findings indicated that transformational leadership did not directly affect organizational innovation; transformational leadership directly affected organizational learning and knowledge management, and organizational learning directly impacted knowledge management. Besides, knowledge management directly affected organizational innovation, yet organizational learning indirectly influenced organizational innovation. Finally, transformational leadership indirectly influenced organizational innovation through the intervening effect of organizational learning and knowledge management. The results indicated that if managers in Turkish HR consulting companies practice a transformational leadership style by taking into account organizational learning and knowledge management, the chance for successful organizational innovation will highly improve.
\end{abstract}

Keywords: HR consulting companies; innovation; transformational leadership

\section{Introduction}

The difference between a leader and his follower lies in innovation says Steve Jobs, a legendary leader who changed the way millions of people live and communicate. Apple and its products are a great example of innovation, and Steve Jobs is an exceptional transformational leader. As stated in Job's quotation, innovation is the sole and the most distinguishing feature of leaders and leading organizations. Today, innovation is a widely discussed topic because it is an important factor in realizing organizational effectiveness (Janssen, Van de Vliert \& West, 2004). Modern organizations have to innovate in order to compete, and they have to recognize that their survival depends on their ability to adapt to changes in their environment. For example, Liao, Fei \& Liu (2008) claimed that organizational success or failure depends on product and process innovation. All of these have led to the need for organizational innovation (Jung, Schoblars Wike 20pcDonough (2000) and Harbone \& Johne (2003) wrote that leadership style has been highlighted as one of the most essential individual influences on organizational innovation since leaders can directly decide to introduce new ideas into an organization, set particular goals and hearten innovation initiatives from their followers. For instance, Ancona \& Caldwell (1987) wrote that transformational leadership has supported and promoted innovation that can make certain the continued existence of an organization, and Howell \& Avolio (1993) linked "transformational leadership" to innovation. Di (2013) stated that transformational leadership is the emerging research topic in innovation which has received a lot of attention by many academicians. Despite the fact that leadership for innovation has been researched recently, the mechanisms for its relationship with the innovation process have not been explicit (Crossan \& Apaydin, 2010). According to Sattayaraksa and Boon-itt (2012), the comprehending of the mechanism through which transformational leaders impact innovation is limited, so researchers have to the processes that intervene the connection between leadership and innovation (Gumusluoglu \& Ilsev, 2009; Sung, 2011) to explain how leadership directly and indirectly affects innovation. To grasp the influence of 
transformational leadership on organizational innovation, it is crucial to find out other closely linked organizational aspects. Researchers have to examine whether transformational leadership directly affects organizational innovation, or whether it indirectly influences innovation through some organizational like organizational learning and knowledge management.

According to Miles (2000), there has been lack of studies on innovation in services, and when the academic literature is reviewed, the amount of empirical research in HR consulting companies is very limited. Innovation in consulting companies is of critical importance due to the fact that consulting companies have to be able to deliver innovative services to their clients to help them to cope with continues change. Moreover, consulting companies have to be innovative in order to generate solid research and knowledge based reports and services so as to help their clients to become more competitive and successful. Consequently, leaders in consulting companies are responsible to transform their company, and they have to display the appropriate leadership style like transformational leadership in order to drive innovation. The problem is that despite the fact that they may try to implement the transformational leadership style, they are not aware of the fact that it is not enough. There is a need for other strategic factors to be managed so that innovation can evolve. That is why leadership in consulting companies has to be transformational, and it has to lead to organizational innovation only through the support of organizational factors such as knowledge management and learning in organizations. A previous study in literature (Noruzy, Dalford, Azhdari et al., 2013) empirically tested the relationships between transformational leadership, learning, knowledge management, innovation and performance in organizations in the manufacturing sector. This present study particularly have the objective to investigate the influence of transformational leadership on organizational innovation through the intervening effects of organizational learning and knowledge management in HR consulting companies in Turkey, and hopefully its results will shed some light to the transformational style of leading and innovation puzzle in this highly determinant sector in a developing

\section{9hperretical Background and Hypotheses}

\subsection{Transformational Leadership and Organizational Innovation}

The transformational leadership theory was first familiarized by Burns (1978), and it was further advanced by Bass and Avolio (1995). Studies conducted by Bass et al. (1987) and Bass and Avolio (1995) defined the "four I's" of transformational leadership. The first "I" that stands for idealized influence was defined as the leader's charisma. It is the leader's behavior that makes the leader to serve as a role model for followers. The leader actually demonstrates extraordinary criterions of ethics and moral behavior, so the leader is reliable, admired and trusted. The second "I" that is inspirational motivation is related with the ways leaders energize their followers by envisioning an attractive future state. They also provide meaning and challenge to their followers' work. Moreover, they demonstrate commitment to ambitious goals, and communicate that the vision is achievable. The third "I" that is intellectual stimulation refers to leadership behaviors which encourage their followers' struggles to be creative and innovative by inquiring suppositions, reframing difficulties and dealing with past situations in novel ways. Finally, the individualized consideration is the fourth "I". It refers for leadership action which pays distinctive attention to the attainment and development need of each individual employee (Bass \& Avolio, 1994).

Organizational innovation is defined as the making beneficial new products or services within the organization (Woodman et al., 1993). Suranyi-Unger (1994) stated that organizational innovation denotes new product, process or system introductions in an organization. Later, some research such as (Podsakoff et al., 1996; Avolio, Bass \& Jung, 1999; Yukl, 2006) inspected leadership style effectiveness on innovation. According to Yukl (2006), leadership has powerful impact on creativity and innovation. Also, Lim \& Lee (2008) emphasized that the academic literature on leadership effectiveness depicts leaders as enablers of innovation. Howell and Higgins (1990) concluded that transformational leaders are role models in exhibiting original conducts to foster the innovative behaviors of followers through idealized influence. Consequently, in studies conducted by Howell \& Avolio (1993) and Lowe, Kroeck \& Sivasubramaniam (1996), transformational leadership has been accepted as more effective than any other leadership styles in facilitating innovation within organizations for it aims transformation and innovation. Bass (1998) concluded that scholars were convinced that transformational leadership is appropriate for promoting and managing innovation in organizations. Jung et al., (2003) stated that transformational leaders organize their followers to guarantee the success of innovations. According to Elkins and Keller (2003), transformational leaders practice inspirational motivation and intellectual stimulation that are important for innovation in an organization. In the academic literature, too much attention is given to the ability of transformational leaders to trigger and sustain organizational innovation (Kavanagh \& Ashkanasy, 2006). Sarros, Cooper \& Santora (2008) wrote that leaders who practice the transformational leadership style can 
motivate their followers beyond the expected performance levels. As a result, this kind of research has also fascinated interest in empirical studies like Jung, Chow \& Wu (2003), Elenkov, Judge \& Wright (2005) and Jung, Wu \& Chow (2008). Some empirical studies such as Keller (1992) and Waldman \& Atwater (1994) supported the idea that transformational leadership ensures positive impact on organizational innovation. Given the theoretical and empirical evidence, the first hypothesis of the present research can be proposed as:

H1: Transformational leadership directly influences organizational innovation.

\subsection{Transformational Leadership and Organizational Learning}

Scholars like Hult, Hurley, Giunipero \& Nichols (2000) stated that transformational leadership is one of the most vital sources for generating organizational learning. Transformational leaders can affect learning by being role models, showing individualized consideration, encouraging intellectual stimulation and increasing inspirational motivation of employees (Coad \& Berry, 1998). As Raferty \& Griffin (2004) wrote that transformational leaders are effective because of their capacity to stimulate their employees intellectually since this kind of stimulation is essential for generating new ideas, experimenting and solving problems and transformational leaders accepted all of these as very positive (Elenkov \& Manev, 2005).

There are several definitions of organizational learning like Shrivastava (1983), Huber (1991), Dimovski (1994) and Bontis et al. (2002). Huber (1991) indicated that organizational learning is information processing that has the goal to stock knowledge in the memory of the organization. He also stated that learning within an organization has four organizational processes. These are knowledge acquisition, information distribution, information interpretation and organizational memory. The knowledge acquisition process is a process for attaining knowledge. Information distribution is actually the process by which sharing information from different sources is done so that it results in new understanding. The process in which distributed information is some commonly understood explanations is defined as information interpretation. The last organizational process related to organizational learning is organizational memory, and it is actually the means for knowledge storing that will be used in the future (Huber, 1991).

Slater \& Narver (1995) and Snell (2001) indicated the positive association between transformational leadership and organizational learning. Moreover, in a recent research conducted by Kurland and Hertz-Lazarowitz (2006) in Israeli non-profit sector, the scholars presented the finding that transformational leadership directly and positively influences has a organizational learning. As a result, hypothesis 2 may be stated as:

\section{$\mathrm{H} 2$ : Transformational leadership affects organizational learning.}

\subsection{Transformational Leadership and Knowledge Management}

The concept of knowledge management has been studied by academics and business people since 1990s. However, an unchanging method which could simply categorize knowledge management has not been defined yet. Knowledge management has five processes that are construction, embodiment, dissemination, use and management (Demarest, 1997). Miller (1999) wrote that knowledge management denotes knowledge acquisition or capturing of knowledge as the creating, gathering, storing, distributing and applying of knowledge. Knowledge creation, transfer and embedding are the three sub-processes of knowledge management according to Armistead (1999). Alavi \& Leidner (2001) stated that organizational knowledge management helps to achieve competitive advantage by identifying, developing and leveraging knowledge. Aguiar (2009) explained that knowledge management contains actions of using, sharing and capturing organizational knowledge.

Transformational leadership enables individuals and organizations to generate, exploit, renew and implement knowledge so as to produce the necessary competences vital for the development of learning within an organization (Aragón-Correa, García-Morales and Cordón-Pozo, 2007). Thus, in the light of this discussion, the third hypothesis is:

H3: Transformational leadership impacts knowledge management.

\subsection{Organizational Learning, Knowledge Management and Organizational Innovation}

Bartlett and Ghoshal (1987) underlined the significance of organizational learning for an organization's continued existence and performance, and Jap (1999) stated that the relationship with partners, suppliers and customers can promote organizational learning. Many scholars have studied the likelihood that the collective organizational learning has a fundamental part in determining innovation (Senge, 1990; Senge, Roberts, Ross, Smith \& Kleiner, 1994). There are some models which clarify the association between 
learning and innovation in organizations (Cohen \& Levinthal, 1990; Kogut \& Zander, 1992; Nonaka \& Takeuchi, 1995; Coombs \& Hull, 1998; Sørensen \& Stuart, 2000; Hall \& Andriani, 2003). Similarly, Calantone et al., (2002) and Tushman \& Nadler, (1986) have noted a positive correlation between organizational learning and innovation. Building from these observations, this research puts forward the next hypothesis:

H4: There is a correlation between organizational learning and innovation.

With the rise of knowledge management as a novel discipline, linking knowledge management and innovation has become compulsory. As Drucker (1993) wrote, "innovation is the application of knowledge to produce new knowledge". The likelihood of organizations to breed innovation results dependents on the former gathering of knowledge which they have captivated (Fiol, 1996). Davenport \& Prusak (1998) stated that explicit and tacit constituents of organizational knowledge have a central part in innovation, so a number of studies explore the correlation between knowledge management and innovation. The relationship between the knowledge created during process innovation actions and the organizational knowledge management was designated in a study conducted by Jang, Hong, Bock \& Kim (2002). Consequently, these have provided some evidence about the link between innovation and knowledge management. Mu, Peng \& Love (2008) agree that there is a solid connection between the flow of knowledge and the company's ability to innovate. Some other academics discussed that innovative results hinged on the preceding accumulation of knowledge that aided innovators to integrate and use new knowledge (Cohen \& Levinthal, 1990). A recent study conducted by Alberto, Victor \& Eulogio (2007) has put forward that knowledge management is clearly linked to organizational innovation. Therefore,

\section{H5: Knowledge management affects organizational innovation.}

Theoretically, a great degree of innovation necessitates organizational learning systems that cultivate, incorporate and use knowledge in the concrete setting (Johannessen, Olsen \& Olaisen, 1999). Argote (1999) proposed processes such as creating knowledge, retaining knowledge, and transferring knowledge in the framework of organizational learning. According to McElroy (2002), the knowledge creation process can be divided into two main processes. The first one is the production of knowledge, and it is identical to the organizational learning process during which novel organizational knowledge is generated. The second one is the integration of knowledge, and it aids knowledge sharing and distribution. Lyles (2003) also examined the learning and the flowing of knowledge in an organization. Besides, organizational learning intensely impacted knowledge management (Aragon-Correa et al., 2007; Skerlavaj, 2009). Later studies of McElroy (2003) and Firestone \& McElroy (2004) supported the idea that organizational learning had a solid influence on knowledge management. Based on this discussion, hypothesis 6 can be formulated as follow:

H6: There is a relationship between organizational learning and knowledge management.

\subsection{Transformational Leadership, Organizational Learning, Knowledge Management and Organizational Innovation}

Carneiro (2000), Plessis (2007) and Dilk et al., (2008) found that innovation is the keystone of every organization. Moreover, innovation is significant since it supports organizations to adjust and react to environmental and technological changes (Damanpour, 2009). As it has already been discussed, innovation is critically important for any kind of an organization. Similarly, innovation is also very important for HR consulting companies. Nusair, Abane \& Bae (2012) postulated that innovation entails evolving and applying new ideas, techniques and procedures to effectively attain organizational objectives. In this study we propose that because of the nature of the consulting business, generating new ideas that will result in innovation is only possible with the use of organizational learning and knowledge management. Managing these two organizational factors is helpful for generating and implementing new knowledge. Managers of HR consulting companies have to be able to enhance knowledge sharing and support organizational learning so that they can leverage on the tacit knowledge of HR consultants and employees. Researchers such as De Jong \& Hartog (2007) defined innovation as the formation of new ideas, products and processes, so leaders in HR companies have to be able to inspire their followers to create groundbreaking ideas and services to generate innovation. As highlighted above, earlier study has affirmed that transformational leadership is the most vital leadership style because it accommodates followers' emotions, values and creativity and cultivates innovation (Saenz, 2011), so leaders in HR companies have to implement the transformational leadership style. As Bass and Riggio (2006) concluded, transformational leaders are catalyzers for innovation because of their actuations that are encouraging inspirational motivation, individualized consideration, intellectual stimulation and self-confidence of the members in an organization. 
Yukl (2013) pointed out that transformational leadership causes subordinates' commitment and produces bigger work quantity and better creative problem solving. For example, leaders who engage in followers' coaching, and training can enrich their skills and inspire them to try original process innovation methods (Chang, 2012).

Adair (1990) and Bass (1991) wrote that transformational leadership is concentrated on the promotion of employees' involvement in collective decisions and activities, so transformational leaders have be skilled in forming teams and directing and supporting them for change and organizational learning (Nadler \& Tushman, 1990; McDonough, 2000; Blackler \& McDonald, 2000). As it has already been discussed, transformational leadership energies learning within an organization by endorsing intellectual stimulation, inspirational motivation and self-confidence of followers (Coad \& Berry, 1998), so transformational leaders in HR consulting companies should be aware of the significance of learning and its relation to organizational innovation.

Transformational leaders reinforce employees' ability for accomplishment by providing the knowledge and resources so that employees can do their jobs (DuBrin, 2012), and Carneiro (2000) has established the link between knowledge management and innovativeness. In some studies like (Bennett \& Gabriel, 1999; Darroch \& MacNaughton, 2002; Lin \& Lee, 2005; Chilton \& Bloodgood, 2010), knowledge management was discussed as serious success organizational aspect and a chief originator for organizational innovation. Additionally, Goh (2005) and Plessis (2007) wrote that knowledge management is a multifaceted and uninterrupted process within organizations, yet it crafts an encouraging atmosphere for innovation to transpire. Consequently, transformational leaders in HR consulting companies should consider the importance of knowledge management in the innovation process. According to Nonaka \& Takeuchi (1995) and Jury, Bordia \& Krebs (2005), transformational leaders can stimulate knowledge sharing. As leaders facilitate the search for new opportunities, employees' responsibilities will be increased and their knowledge sharing will also inevitably flourish (Bass, 1999). Bryant (2003) stated that transformational leadership is responsible for forming a context for leaders to impact the refinement of knowledge, so transformational leadership was considerably associated with knowledge management (Vincent, 2006). Moreover, the mediating effects of knowledge processes on innovation were studied by Andreeva and Kianto, (2011). Building from these observations, this research puts forward the last hypothesis:

H7: Transformational leadership indirectly impacts organizational innovation through the intervening effect of organizational learning and knowledge management.

Considering all of the above stated hypotheses and the proposed research model in (Figure 1), this study aims to find out the significance of the correlations between the four constructs, and then more specifically investigate the influence of transformational leadership on organizational innovation through the intervening effect of organizational learning and knowledge management.

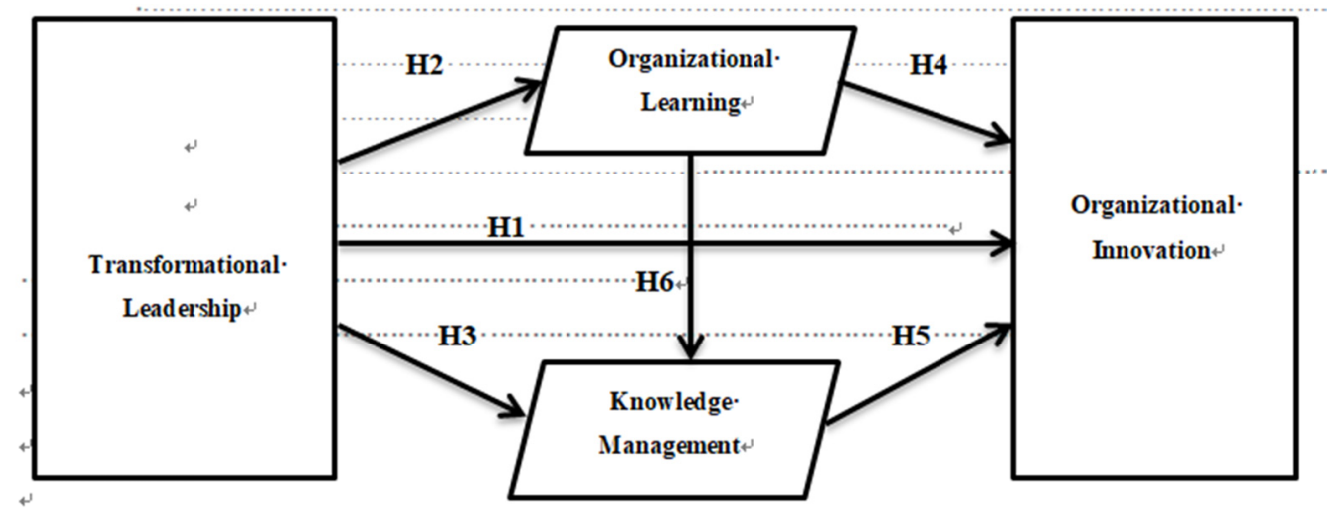

Figure 1. Conceptual Model

\section{Methods}

\subsection{Sample}

The study sample was chosen from the HR consulting industry in Turkey. 218 managers working for small, 
medium size and large HR consulting companies located in Istanbul were randomly selected. The well-known social network platform for business professionals, named LinkedIn was used for sampling.

\subsection{Data Collection}

The questionnaire measuring the constructs was prepared by using Survey Monkey website. The link of the on-line survey questionnaire was sent as a LinkedIn message to 218 participants. From the 218 on-line survey questionnaires, only 70 returned completed.

\subsection{Instruments}

Measuring instruments in the proposed research model included the prevalidated four main constructs of the related theory. Likert type scale, anchored from strongly disagree (1) to strongly agree (5), was used to measure all items.

Transformational Leadership: Podsakoff, Mackenzie \& Bommer (1996). It contained five items. It showed high validity and reliability $(\alpha=0.844$ and composite reliability that equals 0.892$)$.

Organizational Learning: (Garcia-Morales et al., 2007). It comprised four items, and it showed high validity and reliability ( $\alpha=0.849$ and composite reliability that equals 0.899$)$.

Knowledge Management: (Gold et al., 2001). This scale consisted of four items that measure the knowledge processes: acquisition, transfer, integration and conversion. This instrument also showed high validity and reliability ( $\alpha=0.754$ and composite reliability that equals 0.843 ).

Organizational Innovation: (Miller \& Friesen, 1983). To assess organizational innovation, Miller \& Friesen (1983) scale was used. The scale comprised three items, and it showed high validity and reliability $(\alpha=0.845$ and composite reliability that equals 0.909 )

\subsection{Data Analysis}

Based on structural equation modelling, SmartPLS3 software program was implemented to analyze the collected data. Since Bootstrapping is a preferred method especially with small sample sizes Bootstrapping procedure was applied to test the proposed hypotheses and the mediating effects .

\section{Results}

\subsection{Descriptive Characteristics of the Sample}

In terms of gender, $51.4 \%$ of participants were men and $48.6 \%$ were women. $64.3 \%$ of participants were 36 50 years old, $18.6 \%$ were $20-35$ years old, and $17.1 \%$ were $51-70$ years old. In terms of education, $51.4 \%$ of participants hold university degree, $41.4 \%$ hold master's, and $7.1 \%$ hold $\mathrm{PhD}$. Finally when tenure is taken into consideration, $47.8 \%$ of participants have been working from 6 to 15 years at the same company, $44.9 \%$ of participants have from 1 to 5 years tenure, and $7.2 \%$ of participants have been working at the same company for 16 and more years.

\subsection{Relational Analyses}

Table 1 shows Cronbach's alpha and composite reliability results. The values range from 0.754 to 0.909 . Statistically, range above 0.70 is acceptable and over 0.80 is good. As a result, all the scales showed high reliability and validity.

Table 1. Cronbach's Alpha and Composite Reliability

\begin{tabular}{lll}
\hline Variables & Cronbach's Alpha & Composite Reliability \\
\hline Transformational Leadership & 0.844 & 0.892 \\
Organizational Learning & 0.849 & 0.899 \\
Organizational Innovation & 0.845 & 0.909 \\
Knowledge Management & 0.754 & 0.843 \\
\hline
\end{tabular}

Note. $\alpha>0.70$.

Table 2 depicts descriptive statistics and relationships. As anticipated, transformational leadership was linked to organizational learning and knowledge management since the path coefficients were significant. Similarly, the other two correlations that are learning and knowledge management and knowledge management and innovation were also significant. However, the correlation between transformational leadership and innovation was 
insignificant, $(\mathrm{p}=0.402)$. Also, the correlation between organizational learning and innovation was insignificant, $(\mathrm{p}=0.077)$.

Table 2. Means, Standard Deviations, T Statistics, Path Coefficients

\begin{tabular}{lllll}
\hline Variables & M & SDEV & T Statis. & P Values \\
\hline Transformational Leadership $\rightarrow$ Organizational Learning & 0.742 & 0.066 & 11.038 & 0.000 \\
Transformational Leadership $\rightarrow$ Organizational Innovation & 0.100 & 0.134 & 0.839 & 0.402 \\
Transformational Leadership $\rightarrow$ Knowledge Management & 0.448 & 0.113 & 3.942 & 0.000 \\
Organizational Learning $\rightarrow$ Organizational Innovation & 0.241 & 0.133 & 1.772 & 0.077 \\
Organizational Learning $\rightarrow$ Knowledge Management & 0.396 & 0.123 & 3.203 & 0.001 \\
Knowledge Management $\rightarrow$ Organizational Innovation & 0.454 & 0.127 & 3.548 & 0.000 \\
\hline
\end{tabular}

Note. $p<0.05$.

Table 3 summarizes the indirect effect, total effects and their level of significance between predictor and dependent variables in the model. All total effects values and $R^{2}$ values were significant, $(p<0.05)$.

Table 3. Structural model results (total effects and $\mathrm{R}^{2}$ )

\begin{tabular}{lll}
\hline Path & Total effects & $\mathrm{R}^{2}$ \\
\hline Transformational Leadership $\rightarrow$ Organizational Learning & 0.000 & 0.000 \\
Transformational Leadership $\rightarrow$ Organizational Innovation & 0.000 & 0.000 \\
Transformational Leadership $\rightarrow$ Knowledge Management & 0.000 & 0.000 \\
Organizational Learning $\rightarrow$ Organizational Innovation & 0.002 & 0.000 \\
Organizational Learning $\rightarrow$ Knowledge Management & 0.001 & 0.000 \\
Knowledge Management $\rightarrow$ Organizational Innovation & 0.000 & 0.000 \\
\hline
\end{tabular}

Note. $p<0.05$.

Figure 2 illustrates the bootstrapping graphic results of the Structural Equation Model. As illustrated, the factor analysis results for all factors are significant, $(\mathrm{p}<0.05)$. The results from the regression analysis between the four constructs are as follow. Four of the regression analysis are significant, $(p<0.05)$, but two are insignificant. In other words, hypotheses $2,3,5,6$ and 7 were supported. The two insignificant correlations are: the correlation between transformational leadership and innovation, $(\mathrm{p}=0.397)$, and the correlation between organizational learning and innovation, $(\mathrm{p}=0.079)$. Stated differently, hypotheses 1 and 4 were not supported. 


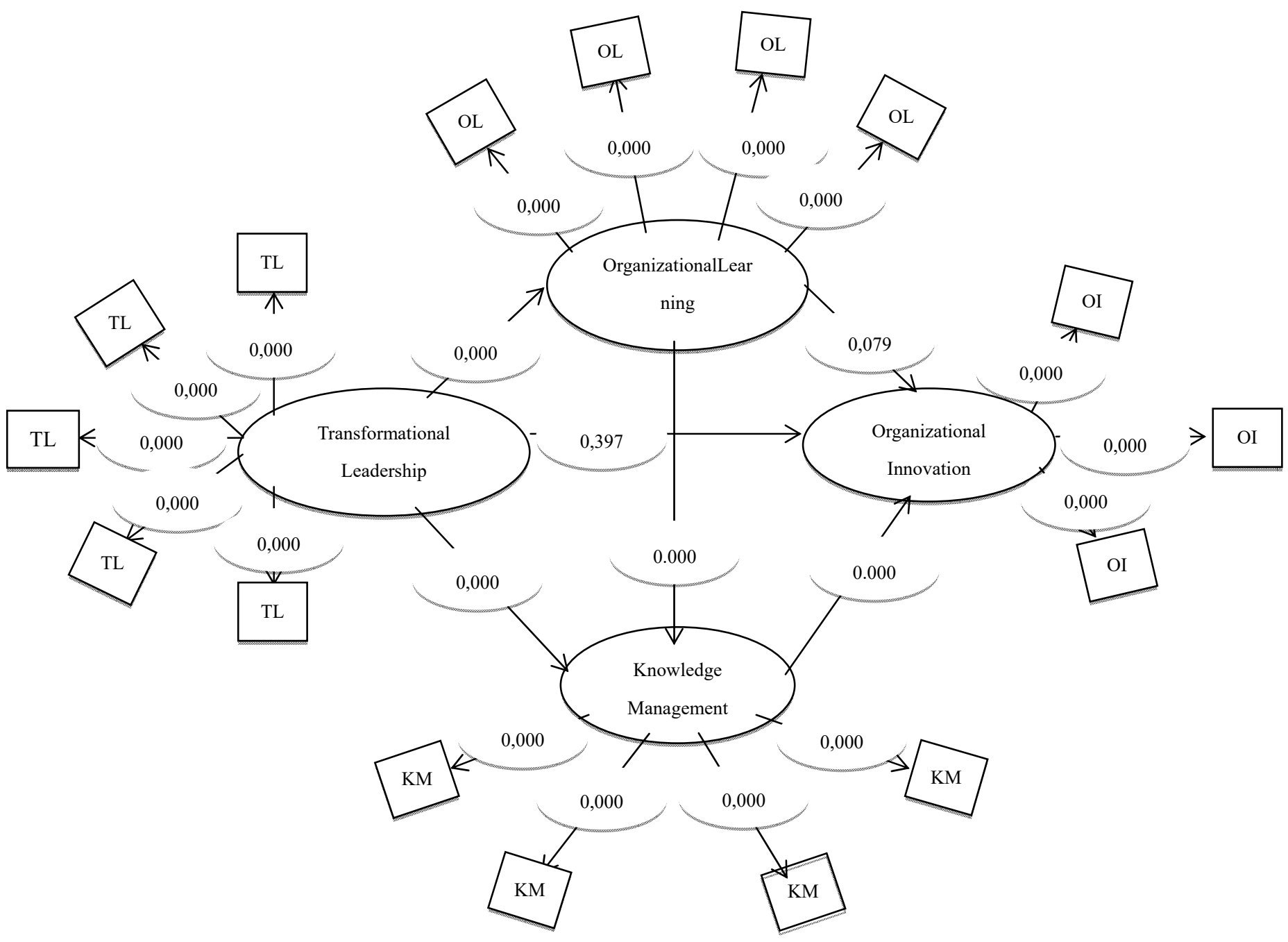

Note. $p<0.05$

Figure 2. SEM Results (Bootstrapping Graphic)

\section{Discussion}

The major contribution of this research was the empirical examination of the proposed research model on HR consulting companies in Turkey as depicted in Figure 2. The key finding of this research is that the first hypothesis was not supported. Thus, we can say that the transformational leadership does not directly influence organizational innovation. In other words, leaders who practice the transformational leadership style will not be able to make their organizations innovative only by being transformational leaders. In hypothesis 2 , it was proposed that the transformational leadership was significantly correlated to organizational learning, so it was confirmed that transformational leadership supports to the improvement of organizational learning. The study provided an opportunity to expose a comprehensive depiction of leaders' role in aiding organizational learning. As argued in the literature, transformational leaders are strategic in creating environment that stimulates the organizational learning.

As discussed in the literature, our research also showed that transformational leadership and knowledge management were related. Consequently, it can be concluded that transformational leaders converse a shared vision and build a favorable social environment which can advise followers to involve in a greater amount of knowledge management activities. In other words, leaders who practice transformational leadership style offer information, stimulus and skills for followers in obtaining, sharing, keeping and applying knowledge. However, organizational learning did not lead to organizational innovation, thus, hypothesis 4 was not supported. Stated differently, the organizational learning which is an outcome of transformational leadership is not enough for organizational innovation. This finding is not consistent with the findings in the literature. Actually, 
organizational learning turned into organizational knowledge is useful for organizational innovation, so it might be useful to investigate knowledge management as the moderating effect in the connection between organizational learning and innovation.

The empirical model demonstrated that knowledge management has a link with organizational innovation as proposed in hypothesis 5. This finding is in accordance with some of the results discussed in the literature, so it should be seriously considered that knowledge management is a vital antecedent of organizational innovation. Hence, by spreading over knowledge management strategies it might be possible to enable the formation of innovative organizational outcomes. Another important contribution of this research is the support of hypothesis 6 and the finding that organizational learning influences knowledge management. Turkish HR consulting companies which are successful in organizational learning are more likely to succeed in allocating and implementing managing knowledge.

The last major contribution of this study is the finding shows that transformational leadership indirectly impacts organizational innovation through learning and knowledge management in HR consulting companies. Thus, organizational learning and knowledge management are like a channel that connects transformational leadership and innovation, so leaders should be aware that knowledge management and organizational learning are critical strategic aspects of organizational innovation. In other words, it should be emphasized that transformational leaders should not overlook the knowledge management and learning; otherwise they will not be able to directly advance organizational innovation.

\subsection{Implications for Management}

This study offered some advice to help leaders to comprehend how to manage knowledge management and learning to influence innovation within their organizations. Thus, the findings of this research have quite a few management implications. First of all, the research reveals the significance of transformational leadership in cultivating knowledge management. It recommends that companies have to promote transformational leadership style, and leaders should practice the transformational leadership style since it affects organizational knowledge management. Transformational leadership that supports knowledge management can lead to organizational innovation. Shortly, transformational leadership empowers employees and companies to use knowledge so as to build the crucial capabilities essential for innovation.

Secondly, this research shows that transformational leadership is a critical element for learning and innovation within an organization. Therefore, managers should be skillful in engaging in transformational leadership behaviors so that they can enhance organizational learning and organizational innovation. Managers have to concentrate on creating a learning context that is fruitful for collective learning and innovation because innovation can only occur when resources are devoted to innovation and when innovative ideas and behaviors are supported. Finally, research findings reveal that transformational leadership indirectly impacts organizational innovation through organizational learning and knowledge management that are mediating the link between transformational leadership and innovation in an organization.

As a result, it should be underlined that if leaders who practice the transformational style of leading overlook knowledge management and learning, these leaders cannot directly enhance innovation. In order to increase organizational innovation, leaders have to use the transformational leadership and apply the intervening effect of knowledge management and organizational learning. All in all, this research helps managers to better comprehend how to implement transformational leadership to increase organizational innovation through organizational learning and knowledge management that and their mediating effect.

\subsection{Conclusion}

By using data collected from Turkish HR consulting companies, and analyzing the data with the help of structural equation modeling, the present study examined the special effects of some organizational factors on organizational innovation. The study findings indicated that transformational leadership was a key contributing factor for learning, knowledge management and innovation within organizations. Generally, the findings demonstrated that transformational leadership did not impact organizational innovation directly, but it impacted it indirectly through the intermediating effect of knowledge management and learning.

\subsection{Limitations of the Study}

Some limitations should be considered when inferring and discussing the outcomes of this research. The first limitation is the cross-sectional data, so this did not permit causal inferences about the longitudinal interplay between the variables analyzed in this study. The second limitation was the short time period for collecting the data. And the last limitation was that the data were provided by only 70 participants. 


\subsection{Recommendations for Further Research}

Future inquiries should center on longitudinal studies as in a longitudinal design where the variables are measured at different points in time, it could provide additional insights. The use of an experimental research design, also, would support causal inferences. It is also recommended that future study collect measures of dependent and independent variables from diverse data sources to lessen any response bias effects. Moreover, cautions ought to be considered while using the research outcomes in different cultures, so readers have to be careful when generalizing the outcomes to diverse cultural settings. Therefore, supplementary investigation in this field can study the connections between those variables in poles apart cultural and organizational setting. Lastly, the proposed research model scrutinizes only some organizational elements influenced by transformational leadership, so it is strongly recommended that forthcoming research examine the influence of transformational leadership on other organizational factors.

\section{Acknowledgement}

We would like to acknowledge Prof. Dr. Ülkü Dicle's support and contribution.

\section{References}

Al-Husseini, S., \& Elbeltagi, I. (2016). Transformational leadership and innovation: a comparison study between Iraq's public and private higher education. Studies in Higher Education, 41(1), 159-181. http://dx.doi.org/10.1080/03075079.2014.927848

Aragon-Correa, A., Garcia-Morales, V., \& Cordon-Pozo, E. (2007). Leadership and organizational learning's role on innovation and performance: Lessons from Spain. Industrial Marketing Management, 36, 349-359. https://doi.org/10.1016/j.indmarman.2005.09.006

Arshi, T., \& Viswanath, S. (2013). Entrepreneurial Leadership and Innovation: An Empirical Study on Organizational Leadership Characteristics and Entrepreneurial Innovation Intensity. American Journal of Social Issues and Humanities, 3(5), 234-243.

Asmawi, A., Zakaria, S., \& Wei, C. (2013). Understanding transformational leadership and R\&D culture in Malaysian universities. Innovation: Management, Policy \& Practice, 15(3), 287-304. http://dx.doi.org/10.1080/03055698.2014.932272

Chen, M., Lin, C., Lin, H., \& McDonough, E. (2012). Does transformational leadership facilitate technological innovation? The moderating roles of innovative culture and incentive compensation. Asia Pacific Journal of Management, 29, 239-264. https://dx.doi.org/10.1007/s10490-012-9285-9

García-Morales, V. J., Lloréns-Montes, F. J., \& Verdú-Jover, A. J. (2007). The effects of transformational leadership on organizational performance through knowledge and innovation. British Journal of Management, 19(4), 299-319. https://dx.doi.org/10.1111/j.1467-8551.2007.00547.x

Gold A.H., Malhotra A. \& Segars A.H. (2001). Knowledge management: an organizational capabilities perspective. Journal of Management Information Systems, 18(1), 185-214. https://doi.org/10.1080/07421222.2001.11045669

Gumusluoglu, L., \& Ilsev, A. (2009). Transformational Leadership and Organizational Innovation: The Roles of Internal and External Support for Innovation. Journal of Product Innovation Management, 26, 264-277. https:// doi.org/10.1111/j.1540-5885.2009.00657.x

Gumusluoglu, L., \& Ilsev, A. (2009). Transformational leadership, creativity, and organizational innovation. Journal of Business Research, 62, 461-473. https://doi.org/10.1016/j.jbusres.2007.07.032

Han, S., Seo, G., Li, J., \& Yoon, S. (2016). The mediating effect of organizational commitment and employee empowerment: how transformational leadership impacts employee knowledge sharing intention. Human Resource Development International, 19(2), 98-115. http://dx.doi.org/10.1080/13678868.2015.1099357

Jiménez-Jiménez. D., \& Sanz-Valle, R. (2011). Innovation, organizational learning, and performance, Journal of Business Research, 64, 408-417. https://doi.org/10.1016/j.jbusres.2010.09.010

Kollmann, T., Stöckmann, C., Krell, P., Peschl, A., \& Buchwald, S. (2013). Integrating Dependency on the Leader and Empowerment into Transformational Leadership-Creative Performance Relationship. Central European Business Review, 2(1), 7-14.

Leal-Rodriguez, A., Roldan J., Leal, A., \& Ortega-Gutierrez, J. (2013). Knowledge management, relational learning, and the effectiveness of innovation outcomes. The Service Industries Journal, 33(13-14), 
1294-1311. http://dx.doi.org/10.1080/02642069.2013.815735

Miller, D., \& Friesen, P. H. (1983). Strategy-making and environment: The third link. Strategic Management Journal, 4(3), 221-235. https://doi.org/10.1002/smj.4250040304

Noruzy, A., Dalfard, V., Azhdari, B., Nazari-Shirkouhi, S., \& Rezazadeh, A. (2013). Relations between transformational leadership, organizational learning, knowledge management, organizational innovation, and organizational performance: An empirical investigation of manufacturing firms. International Journal of Advanced Manufacturing Technology, 64, 1073-1085. https://doi.org/10.1007/s00170-012-4038-y

Podsakoff, P. M., Mackenzie, S. B., \& Bommer, W. H. (1996). Transformational leader behaviors and substitutes for leadership determinants of employee satisfaction, commitment, trust and organizational citizenship $\begin{array}{llll}\text { behaviors. } & \text { Journal } & \text { 259-298. }\end{array}$ http://psycnet.apa.org/doi/10.1016/S0149-2063(96)90049-5

Ramírez, A., Vasauskaite, J., \& Kumpikaite, V. (2012). Role of Knowledge Management within Innovation and Performance. Economics and Management, 17(1), 381-389.

Sarros, J., Cooper, B., \& Santora, J. (2008). Building a Climate for Innovation through Transformational Leadership and Organizational Culture. Journal of Leadership \& Organizational Studies, 15(2), 145-158. https://doi.org/10.1177/1548051808324100

Sattayaraksa, T., \& Boon-itt, S. (2015). A Study of CEO Transformational Leadership, Organizational Factors and Product Innovation Performance: Scale Development and a Theoretical Framework. International Journal of Innovation Science, 7(2), 107-126. https://doi.org/10.1260/1757-2223.7.2.107

Slatten, T., \& Mehmetoglu, M. (2015). The Effects of Transformational Leadership and Perceived Creativity on Innovation Behavior in the Hospitality Industry. Journal of Human Resources in Hospitality \& Tourism, 14, 195-219. http://dx.doi.org/10.1080/15332845.2014.955557

Slavković, M., \& Babić, V. (2013). Knowledge Management, Innovativeness and Organizational Performance: Evidence from Serbia. Economic Annals, LVIII(199), 85-107.

Zagoršek, H., Dimovski, V., \& Škerlavaj, M. (2009). Transactional and transformational leadership impacts on organizational learning. Journal of East European Management Studies, 2, 144-165.

\section{Appendix}

Table 4. Measurement instruments summary

Measures, Sources and Items

Transformational Leadership, (Podsakoff, Mackenzie \& Bomme, 1996)

The firm's management is always on the lookout for new opportunities for the Unit / department /organization.

The firm's management has a clear common view of its final aims.

The firm's management succeeds in motivating the rest of the company.

The firm's management always acts as the organization's leading force.

The organization has leaders who are capable of motivating and guiding their colleagues on the job.

Organizational Learning, (Garcia-Morales et al., 2007)

The organization has learned or acquired much new and relevant knowledge over the last three years.

Organizational members have acquired some critical capacities and skills over the last three years.

The organization's performance has been influenced by new learning it has acquired over the last three years.

The organization is a learning organization.

Knowledge Management, (Gold et al., 2001)

Our firm has processes for integrating different sources and types of knowledge.

Our firm has processes for converting competitive intelligence into plans of action.

Our firm has processes for acquiring knowledge about our business partners.

Our firm has processes for exchanging knowledge with our business partners.

Organizational Innovation, (Miller \& Friesen, 1983)

The rate of introduction of new products or services into the organization has grown rapidly.

The rate of introduction of new methods of production or delivery of services into the organization has grown rapidly.

In comparison with its competitors the organization has become much more innovative. 


\section{Copyrights}

Copyright for this article is retained by the author(s), with first publication rights granted to the journal.

This is an open-access article distributed under the terms and conditions of the Creative Commons Attribution license (http://creativecommons.org/licenses/by/4.0/). 